\title{
IMPLEMENTASI PEMURIDAN KONTEKSTUAL KEPADA PELAYANAN PEMUDA DALAM MENUNJANG KEDEWASAAN ROHANI
}

Oleh:

ASTRI

MAHASISWA INSTITUT AGAMA KRISTEN NEGERI (IAKN) TORAJA

Jalan Poros Makale-Makassar Km 11,5 Buntu Tangti, Mengkendek

Kabupaten Tana Toraja, Sulawesi Selatan 91871

Email: allingastrid12@gmail.com

\begin{abstract}
Abstrak
Memasuki era globalisasi yang memudahkan setiap orang untuk mengakses apapun, kecepatan menerima informasi, mempercepat dan mempermudah aktifitas manusia namun tidak dapat dipungkiri akan ada dampak negatif dari perkembangan zaman ini, Gereja mulai terlena dengan perkembangan tekhnologi dan mengabaikan pelayanan pemuda, kebanyakan sekarang lebih mengutamakan pengetahuan, iptek dan mengabaikan pengetahuan akan pertumbuhan iman, kedewasaan iman yang lebih penting dari itu. Berdasarkan hal tersebut maka sebagai Gereja yang adalah tubuh Kristus hendaknya terus memperlangkapi pemuda selaku generasi gereja dalam memperhatikan pelayanan pemuda dalam menunjang kedewsaan rohani sehinnga mereka mampu bertahan hidup dalam situasi dan kondisi. Gereja harus terus memberi pelayanan yang aktif. Salah satu peran aktif adalah melalui pemuridan kontekstual/KTBK yang didalamnya terdapat Pembelajaran Alkitab yang kontinu.
\end{abstract}

Kata Kunci: Pemuridan Kontekstual, Pelayanan pemuda, pendewsaan iman, pelayanan pemuda dan pendewasaan iman 


\section{Pendahuluan}

Memasuki era globalisasi sangat mendatangkan berbagai pengaruh dalam dunia pendidikan, iman. Di era global yang cenderung bersifat mendunia dan individual. ini merupakan suatu perilaku masyarakat yang mengikuti perkembangangan era global yang tidak sesuai dengan ajaran agama. Persoalan yang muncul dalam era global ini adalah lembaga-lembaga lebih mengutamakan ilmu pengetahuan dan teknologi daripada mengutamakan ilmu iman atas setiap manusia, khususnya bagi pemuda selaku generasi bangsa akibatnya mereka lebih menguasai dan memahami ilmu pengetahuan umum, akan tetapi lemah dalam segi ilmu agama. Kondisi seperti ini sangat dikhawatirkan akan berakibat terbentuknya pribadi dan moral kurang baik apalagi kebobrokan iman.

Globalisasi merasuk begitu cepat ke seluruh pelosok dari kota besar hingga kepelosok sekalipun. Globalisasi adalah konteks saat ini dimana Gereja ada. Globalisasi adalah konteks dimana generasi muda Gereja memaknai kedewasaan iman dalam globalisasi. Globalisasi turut memberi dampak bagi kehidupan beragama. Gereja yang merupakan perkumpulan orang-orang yang percaya pada Kristus seringkali melupakan tanggung jawabnya terhadap pelayanan kaum muda. Kaum muda merupakan golongan manusia yang masih memerlukan pembinaan atau pengembnagan ke arah yang lebih baik, karena pada prinsipnya pemuda merupakan generasi yang terus bertumbuh, kaum muda adalah masa transisi dan dalam masa ini kaum muda sangat memerlukan pembinaan pelayanan kaum muda untuk beralih dara masa transisi menuju kedewasaan rohani. ${ }^{1}$ Sehingga untuk menyikapi persoalan ini Gereja perlu mengupayakan pembinaan terhadap pemuda.

Salah satu pembelajaran dari Kekristenan adalah pemuridan. Pemuridan adalah hubungan antara guru dan murid didasarkan pada pola Kristus dan kehidupan-Nya yang diajarkan kepada Murid-Nya. ${ }^{2}$ Pemuridan kontekstual diharapkan memberikan dampak yang baik dikehidupan masa kini. Beberapa penelitian sebelumnya salah satunya adalah pemuridan kontekstual memberikan dampak bagi para alumnus untuk kembali dalam tugas

\footnotetext{
${ }^{1}$ Robi I. Chandra, Pemimpin yang Meraih kawula Muda (Bekasi: Seri Kepemimpinan Bina Warga 1997) 6.

${ }^{2}$ Alton Garrison, "Pemuridan yang Berhasil 360, (Jawa Timur: Gandum Mas, 2012), 19
} 
pelayanannya. ${ }^{3}$ Demikian pemuridan kontekstual diharapkan dapat memberikan dampak bagi pelayanan pemuda kristen dalam menunjang kedewasaan rohani.

\section{Rumusan Masalah}

Penelitian ini beranjak dari fokus masalah, kurangnya perhatian Gereja dalam pelayanan pemuda sehingga muncullah suatu rumusan bagaimana pemuridan kontekstual bagi pelayanan pemuda dalam menunjang kedewasaan rohani?

\section{Tujuan}

Penelitian ini bertujuan untuk mengetahui bagaimana pemuridan kontekstual kepada pelayanan pemuda dalam menunjang kedewasaan rohani.

\section{Manfaat}

Manfaat dari penelitian ini adalah: pertama mengerti dan menyadari pentingnya pelayanan bagi pemuda dalam menunjang kedewasaan rohani, kedua memberikan gambaran bagi gereja untuk lebih memberi perhatian dan pelayanan kepada pemuda serta menciptakan bentuk pelayanan yang relevan. Ketiga, sebagai arahan untuk setiap pelayan, hamba Tuhan dalam mengaplikasikan bentuk Pemuridan Kontekstual kepada seluruh orang percaya.

\footnotetext{
${ }^{3}$ Yulia and Kezia Yemima, "MODEL PEMURIDAN KONSELING ALUMNUS PERGURUAN TINGGI LULUSAN BARU (FRESH GRADUATE) YANG MENGINGKARI PANGGILAN PELAYANAN," Jurnal Gamaliel: Teologi praktika 1, no. 1 (2019) :26.
} 


\section{Pembahasan}

\section{Pemuridan Kontekstual}

Pemuridan Kontekstual merupakan suatu kelompok yang mau berkomitmen untuk bertumbuh dan biasanya terdiri atas tiga sampai enam orang. Pemuridan Kontekstual adalah salah satu model pemuridan yang fokus dalam mempelajari kebenaran Alkitab secara holistikkontekstual dan dapat diaplikasikan dalam kehidupan sehari-hari. ${ }^{4}$ Pemuridan merupakan suatu proses butuh waktu yang cukup lama, tujuan utama orang yang dewasa dalam Kristus adalah pada akhirnya untuk memperkenalkan kristus pada orang lain. Penelitian mengenai Pemuridan kontekstual terus diekplorasi sehingga dapat digunakan secara maksimal dalam setiap pelayanan pemuridan.

\section{Pelayanan Kepada pemuda}

Berdasarkan tugas amanat agung Tuhan Yesus secara tegas dan jelas, Yesus Kristus memberikan tugas dan perintah kepada gereja-gereja, serta mereka yang percaya pada-Nya sebagai, untuk melaksanakan tugas dan tanggung jawab agar semua bangsa menjadi muridNya (Amanat agung Mat 28:18-20), maka ada tiga panggilan Gereja yaitu, pertama Kolonia artinya persekutuan gereja terbentuk karena adanya persekutuan orang-orang percaya, gereja harus menciptakan persekutuan setiap anggota tubuh Kristus harus memperhatikan satu sama lain. kedua Marturia bermakna kesaksian, bersaksi menceritakan realitas yang sebenarnya, Marturia tidak hanya dalam bentuk khotba dan nyanyian, marturia tidak terbatas hanya dalam ruang gereja saja melainkan dimanapun orang percaya berada. Ketiga Diakonia artinya melayani, ini bentuk kepedulian gereja dalam mewujudkan tugas panggilannya dalam memenuhi visi misi pelayanan gereja kepada masyarakat luas bahkan segala bangsa. ${ }^{5}$ Tidak dapat disangkali bahwa tugas panggilan gereja ini sangat penting bagi pelayanan pemuda kristen yang membutuhkan pembinaan dalam upaya pendewasaan rohani didalam Yesus Kristus.

\footnotetext{
${ }^{4}$ Daniel Fajar Panuntun and Eunike Paramita, "HUBUNGAN PEMBELAJARAN ALKITAB TERHADAP NILAI-NILAI HIDUP BERBANGSA DALAM PEMURIDAN KONTEKSTUAL (KELOMPOK TUMBUH BERSAMA KONTEKSTUAL)," Jurnal Gamaliel: Teologi praktika 1, no. 1 (2019) :107.

${ }^{5}$ Jappy Pello Kila, “TUGAS PANGGILAN GEREJA”, Jurnal Guru Indonesia: PENCIPTAAN MANDAT DARI TUHAN ALLAH KEBUTUHAN HIDUP DAN KEHIDUPAN. 4
} 
Pembelajaran Alkitab sehari-hari dapat dilakukan melalui berbagai kegiatan seperti morning devotion (saat teduh). Indikator-indikator yang menjadi acuan pembelajaran Alkitab adalah hal-hal sebagai berikut: kerajinan dalam membaca FirmanTuhan, dampak psikologis ketika tidak membaca Alktiab, memiliki kelompok KTBK yang aktif, merasakan adanya pertumbuhan iman, dan kebiasaan dalam membaca FirmanTuhan. ${ }^{6}$ Memiliki kelompok KTBK diharapkan difasilitasi dari gereja agar pemuda boleh ikut dalam setiap proses menuju pendawasaan iman.

Pemuda terkadang cepat merasa bosan maka dari itu untuk mengimbanginya perlu diadakannya Ritrit, namun yang menjadi syarat disini adalah bagaimana strategi untuk ritrit yang efektif sebagai bagian dari pelayanan Gereja. Sasaran dari ritrit bukanlah kelancaran atau sukses melainkan kesempatan untuk bertumbuh. Inti utama dari pelayanan kaum muda adalah pemuridan (Mat 28:19-20) memuridkan pemuda agar dapat menjadi serupa dengan Kristus dalam perilakunya (Ef 4:13; Rm 8:29) tujuan utama dari pemuridan pemuda adalah agar mereka dapat menjadi pembuat murid Kristus yang berlipat ganda serta mengalami kedewasaan rohani. ${ }^{7}$ Pembimbing Ritrit hendak menyusun acara sedemikian rupa yang mengantarkan pemuda pertumbuhan rohani melalui kegiatan tersebut agar ritrit tidak hanya sekadar jalan-jalan saja.

\section{Kedewasaan Rohani}

Kedewasaan yaitu munculnya ciri-ciri kepribadian dan perilaku melalui proses pertumbuhan dan mampu mengemban tanggung jawabnya sendiri. Sama seperti makhluk hidup melewati proses pendewasaan secara fisik, semua orang percaya juga harus melewati proses pendewasaan secara rohani. Dalam perkembangan kerohanian, kedewasaan adalah gaya hidup kristiani yang berkembang melalui belajar prinsip-prinsip kristus dan menerapkannya dengan kuasa yang berasal dari Roh Kudus. Dengan demikian tiap-tiap manusia kepunyaan Allah diperlengkapi dengan sempurna untuk setiap perbuatan baik (2 $\operatorname{Tim} 3: 16,17){ }^{8}$

\footnotetext{
${ }^{6}$ Ibid.

${ }^{7}$ Warren, Mark Senter, “Pedoman Lengkap Untuk Pelayanan Kaum Muda, ”( Bandung: Yayasan Kalam Hidup, 1999) Jilid 1, 244.

${ }^{8}$ Warren, Mark Senter, “Pedoman Lengkap Untuk Pelayanan Kaum Muda, ”( Bandung: Yayasan Kalam Hidup, 1999) Jilid 2, 37.
} 
Adapun fakta-fakta dari kedewasaan Rohani, kedewasaan tidak ditentukan oleh usia, pemazmur menunjukkan bahwa orang muda mungkin lebih mengerti daripada orang tua bila ia merenungkan Firman Allah dan mengikuti perintah-perintahNya. Jadi usia tidak menentukan kedewasaan namun ketaatan pada Firman menjadi bukti kedewasaan. kedewasaan tidak ditentukan oleh pendidikan, kedewasaan adalah komitmen untuk bertumbuh dan berkembang secara rohani seumur hidup, kedewasaan adalah proses, kedewasaan menuntut disiplin. ${ }^{9}$ pertumbuhan rohani tidak tumbuh secara otomatis, kedewasaan rohani butuh proses tidak ada jalan pintas untuk menjadi dewasa, menjadi dewasa membutuhkan waktu, perjuangan dan ketetapan hati maka bertumbuhlah dalam kasih karunia dan dalam pengenalan akan Tuhan dan Juruselamat kita, Yesus Kristus. BagiNya kemuliaan, sekarang dan sampai selama-lamanya (2 Ptr. 3:18).

Menjalani kehidupan yang dewasa, orang percaya yang dewasa akan mengembangkan dan memelihara kebiasaan untuk melakukan saat teduh secara pribadi setiap hari, berdoa dan membaca Alkitab setiap hari penting untuk kedewasaan. kebiasaa ini merupakan kunci utama dalam kehidupan orang percaya. Dalam Yak 1:21-25, Yakobus mengingatkan orang-orang Kristen Perjanjian Baru agar mereka membiasakan diri membaca dan mempelajari Firman Allah. Setiap orang Kristen harus memiliki wajtu saat teduh untuk bersekutu dengan Allah. Tiap orang dewasa masih perlu bertumbuh dalam kedewasaan kepribadian dan kedewasaan iman. Hal itu dianggap sesuai dengan pesan Efesus 4:15 bahwa setiap orang masih membutuhkan pertumbuhan dalam segala hal kearah Kristus. ${ }^{10}$

\section{Pelayanan Pemuda dan Kedewasaan Rohani}

Melihat pentingnya pelayanan kepada pemuda dimungkinkan adanya pengaruh pelayanan kepada pemuda dalam menunjang kedewasaan rohani, yang berdampak bagi pribadi pemuda maupun bagi orang-orang yang berada disekitarnya, dua variabel ini akan saling berkaitan dimana pelayanan kepada pemuda dapat membawa kedewasaan rohani bagi kaum pemuda.

\footnotetext{
${ }^{9}$ Alton Garrison, "Pemuridan yang Berhasil 360, (Jawa Timur: Gandum Mas, 2012), 17

${ }^{10}$ Binsen S. Sidjabat, “Mendidik Warga Gereja Melalui Seri Selamat”, (Jakarta: Gunung Mulia 2018) 110
} 


\section{Kesimpulan dan saran}

Kesimpulan dari penelitian ini adalah pelayanan kepada kaum muda pada pemuridan kontekstual/KTBK memiliki hubungan positif dengan pemahaman nilai-nilai kedewasaan rohani dengan kesadaran tugas panggilan gereja dalam pelayanan bagi pemuda yang dapat menunjang kedewasaan rohani.

Saran dari penelitian ini adalah: pertama, mengaplikasikan Pemuridan Kontekstual/KTBK secara konsekuen kepada pemuda Kristen sehingga didapatkan generasigenerasi penerus gereja yang dewasa dalam iman kepada Yesus Kristus. Kedua, Pemuridan Kontekstual/KTBK dapat dijadikan rujukan dalam pelayanan kaum muda secara kontekstual. Gereja harus terus memperlengkapi pemuda Kristen dengan peningkatan pelayanan pada pemuda dalam pemuridan kontekstual. 


\section{Daftar Pustaka}

Alton Garrison, 2012, "Pemuridan yang Berhasil 360, Jawa Timur: Gandum Mas

Yulia and Yemima Kezia, 2019, "MODEL PEMURIDAN KONSELING ALUMNUS PERGURUAN TINGGI LULUSAN BARU (FRESH GRADUATE) YANG MENGINGKARI PANGGILAN PELAYANAN," Jurnal Gamaliel: Teologi praktika 1, no. 1

Panuntun, Daniel and Paramita Eunike, 2019, "HUBUNGAN PEMBELAJARAN ALKITAB TERHADAP NILAI-NILAI HIDUP BERBANGSA DALAM PEMURIDAN KONTEKSTUAL (KELOMPOK TUMBUH BERSAMA KONTEKSTUAL),” Jurnal Gamaliel: Teologi praktika 1, no. 1

Warren, Mark Senter 1999, “Pedoman Lengkap Untuk Pelayanan Kaum Muda,” Bandung: Yayasan Kalam Hidup, Jilid 1

Warren, Mark Senter, 1999, "Pedoman Lengkap Untuk Pelayanan Kaum Muda,"( Bandung: Yayasan Kalam Hidup, Jilid 2

Alton Garrison, 2012, "Pemuridan yang Berhasil 360, Jawa Timur: Gandum Mas

Robi I. Chandra,1997, Pemimpin yang Meraih kawula Muda, Bekasi: Seri Kepemimpinan Bina Warga

Jappy Pello Kila, “TUGAS PANGGILAN GEREJA”, Jurnal Guru Indonesia: PENCIPTAAN MANDAT DARI TUHAN ALLAH KEBUTUHAN HIDUP DAN KEHIDUPAN. 4

Binsen S. Sidjabat, 2018, "Mendidik Warga Gereja Melalui Seri Selamat”, Jakarta: Gunung Mulia 